\title{
Dra. Odette Farrú Albohaire Con la pediatría en el corazón
}

\begin{abstract}
Virtuosa concertista en piano y destacada profesora, tiene el mérito de ser la primera mujer en ingresar a la Sociedad Chilena de Cardiología, en el año 1961, convirtiéndose en un referente para todas las generaciones que se formaron en esta entidad. Una muestra irrefutable del enorme valor que le dio a su especialidad y que le ha traído de vuelta innumerables reconocimientos, como el de ser nombrada Maestra de la Cardiología Chilena.
\end{abstract}

Formada en la Universidad de Chile y pionera en el departamento de cardiología pediátrica del Hospital Roberto del Río, la Dra. Odette Farrú es una de las máximas exponentes nacionales de la especialidad, quien se ha destacado a lo largo de los años por ser una de las primeras mujeres en ejercer esta rama de la medicina y por ser formadora de varias generaciones con gran éxito.

Ejerció en dicho centro formador durante 45 años, hasta donde llegó invitada por el Doctor Julio Meneghello, en el año 1965, para unirse a la incipiente unidad de cardiología pediátrica en esa época. Reconoce que ahí comenzó verdaderamente su carrera, con dedicación exclusiva hasta el año 2010, cuando a raíz de un shock séptico debió jubilarse.

Dueña de innumerables dotes, destacada investigadora, escritora y docente en varios idiomas, a su título de medicina se suma el de concertista en piano, y los múltiples reconocimientos recibidos a lo largo de su carrera, entre los que destaca el de Maestra de la Cardiología Chilena, otorgado por la Sociedad Chilena de Cardiología y Cirugía Cardiovascular por primera y única vez a una mujer en el año 2013.

Haciendo un repaso de lo que ha sido su importante carrera, en esta entrevista la Dra. Farrú destaca los grandes avances de la medicina en su área desde que supiera muy precozmente que lo suyo era la cardiología, y que una casualidad la llevara a enamorarse de la cardiología pediátrica, a la que dedicó su vida, e invita a las nuevas

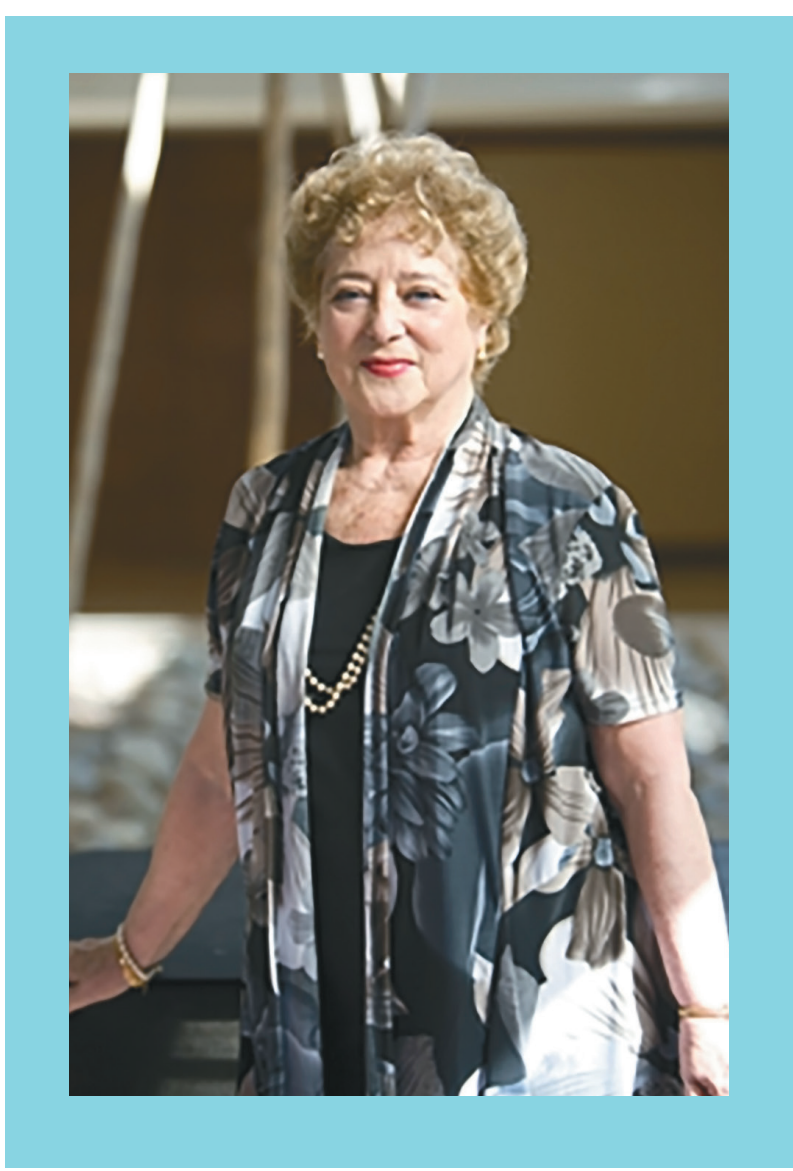
generaciones a trabajar con pasión y esfuerzo para sen- 


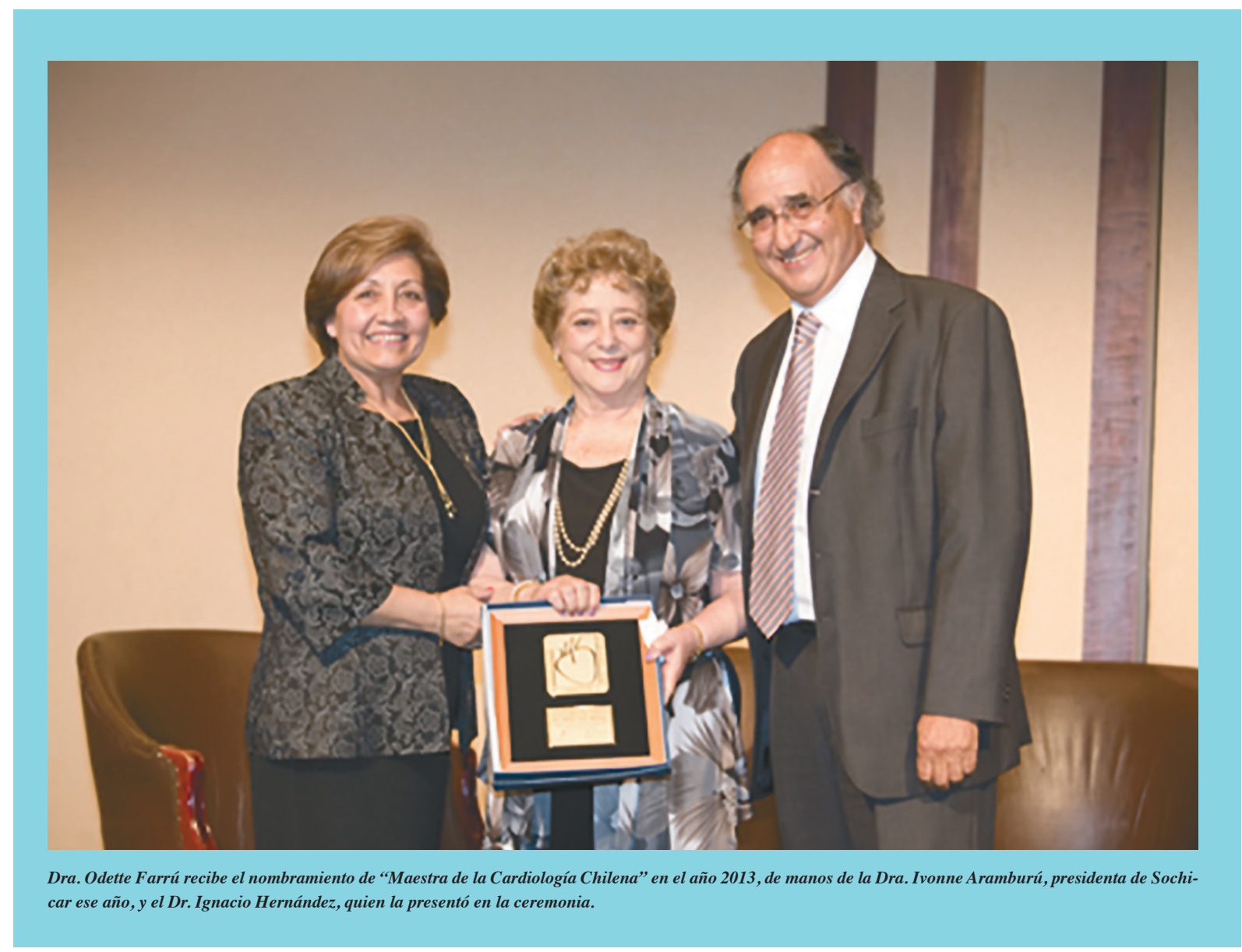

tar las bases de la felicidad.

\section{¿Cuándo supo que ejercería la medicina?}

Fue por azar y se dio de una manera muy especial, porque yo quería seguir estudiando la carrera de concertista en piano, pero obtuve el puntaje más alto del país en el Bachillerato, así es que todos me instaron a estudiar algo más "formal" y me decidí por Medicina. Me formé en la Universidad de Chile y fui la mejor alumna egresada del año 1959; de hecho, obtuve el premio del
Colegio Médico por esta razón, al mismo tiempo que el Doctor Pablo Casanegra era el mejor alumno egresado de la Universidad Católica. A pesar de eso, seguí mi deseo de estudiar en el Conservatorio Nacional de Música, y estando en quinto año de medicina, di mi examen de concertista en piano; dos años más tarde, me recibí de médico.

\section{¿Cómo recuerda los inicios de su carrera?}

Fue bien curioso, porque en segundo año de medicina 

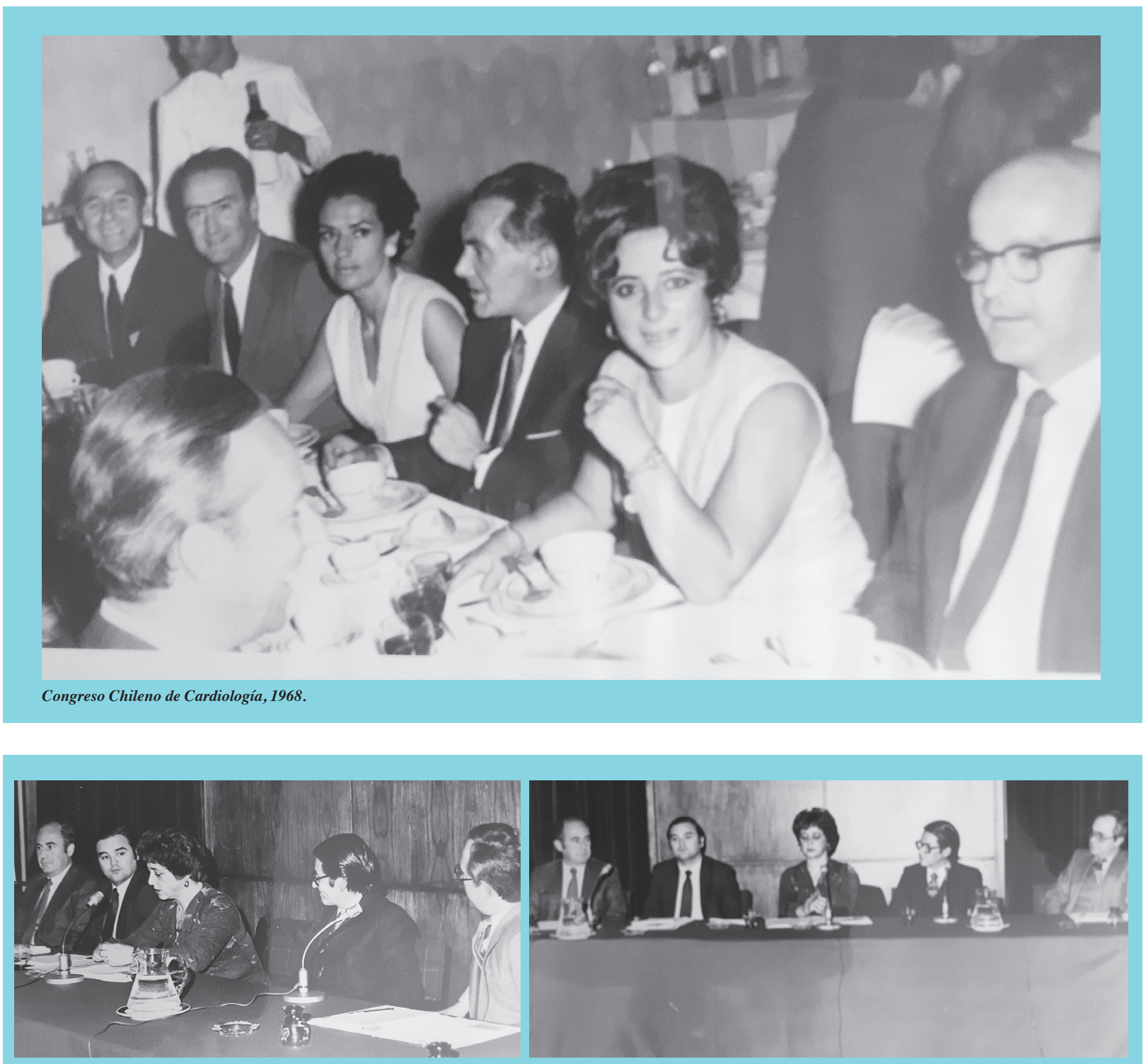

Dra. Farrú dirigiendo una mesa redonda en el Congreso Chileno de Cardiología, 1982.

me encontré con el libro de Fisiopatología del profesor Bernardo Houssey, donde conocí el aparato circulatorio y me enamoré de él, y desde entonces supe que iba a ser cardióloga, aunque en ese momento no conocía aún la maravilla de la cardiología pediátrica. Durante la carrera, cada vez que estaba en el Hospital haciendo algún trabajo, me escapaba al Servicio de Cardiología a ver lo que hacían, y en cuarto año de Medicina, el Dr. Gonzalo Sepúlveda me llevó al Hospital J.J. Aguirre a hacer un cateterismo cardíaco, que fue lo más emocionante para mí. Cuando me recibí, me topé con las cardiopatías congénitas y sentí que eran lo máximo, un área muy desafiante, gratificante y útil para la sociedad, pues podías transformar a un niño enfermo en uno sano, así es que comencé a especializarme en ella. Cuando comencé a ejercerla full time en el Hospital Roberto del Río, en 1965, junto a mi gran maestro, el Dr. Gastón Duffau Ortiz, partimos solo con un estetoscopio y un electrocardiógrafo, y pese a ser considerados como raros en esa época, fuimos pioneros e incorporamos año tras año nuevas tecnologías. Por ejemplo, yo fui la primera pediatra que utilizó la fonocardiografía como trazado de referencia en la auscultación cardíaca, y presenté los resultados en uno de los primeros Congresos, los cuales fueron luego publicados en Chile. 
¿Qué avances tecnológicos destaca en la especialidad, desde sus inicios a la fecha?

Yo alcancé a ver casi todos los avances, y creo que uno de los más importantes de la época ha sido el cateterismo intervencional, que ha permitido curar cardiopatías congénitas sin hacer una toracotomía, es decir, sin abrir el tórax, y sin circulación extracorpórea. El cateterismo intervencional permite disminuir la mortalidad, hecho notorio en los últimos años. Otro avance ha sido la cirugía correctora en los primeros meses de vida, porque evita muchas cirugías paliativas previas. Hoy se opera a los niños directamente, a veces, con un sistema quirúrgico híbrido, y de esa manera se gana tiempo, porque trabajan el cirujano y quien hace el cateterismo intervencional al mismo tiempo.

\section{¿Cuáles destacaría como los hitos más importantes de su carrera?}

Por mencionar algunos: fui nombrada Fellow of the American College of Cardiology (ACC), en 1970, hice una beca en Alemania (un año y medio en la Universidad de Heidelberg), becas de 3 meses en varias oportunidades en Francia (Universidad de Lille), fui nombrada Miembro Correspondiente Latinoamericano de la Sociedad Europea de Cardiología pediátrica (único miembro correspondiente latinoamericana de esta entidad en esa época). Alcancé el título de Profesor Titular de Pediatría de la Universidad de Chile, colaboré en la publicación de diversos capítulos de temas cardiológicos en libros de Pediatría (algunos en alemán, otros en francés) más de 100 trabajos publicados en revistas nacionales y extranjeras, muchos de ellos seleccionados para premios

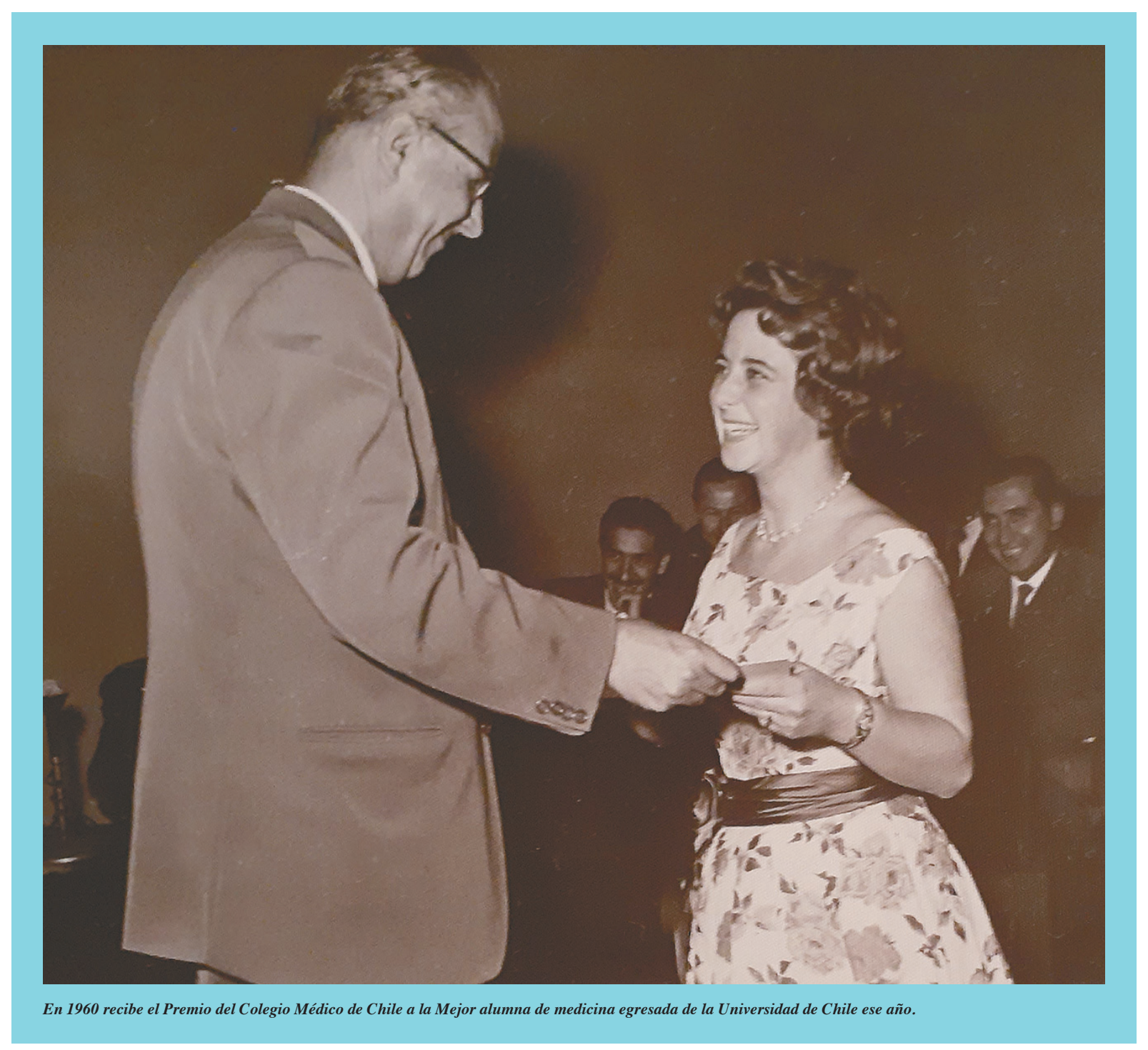




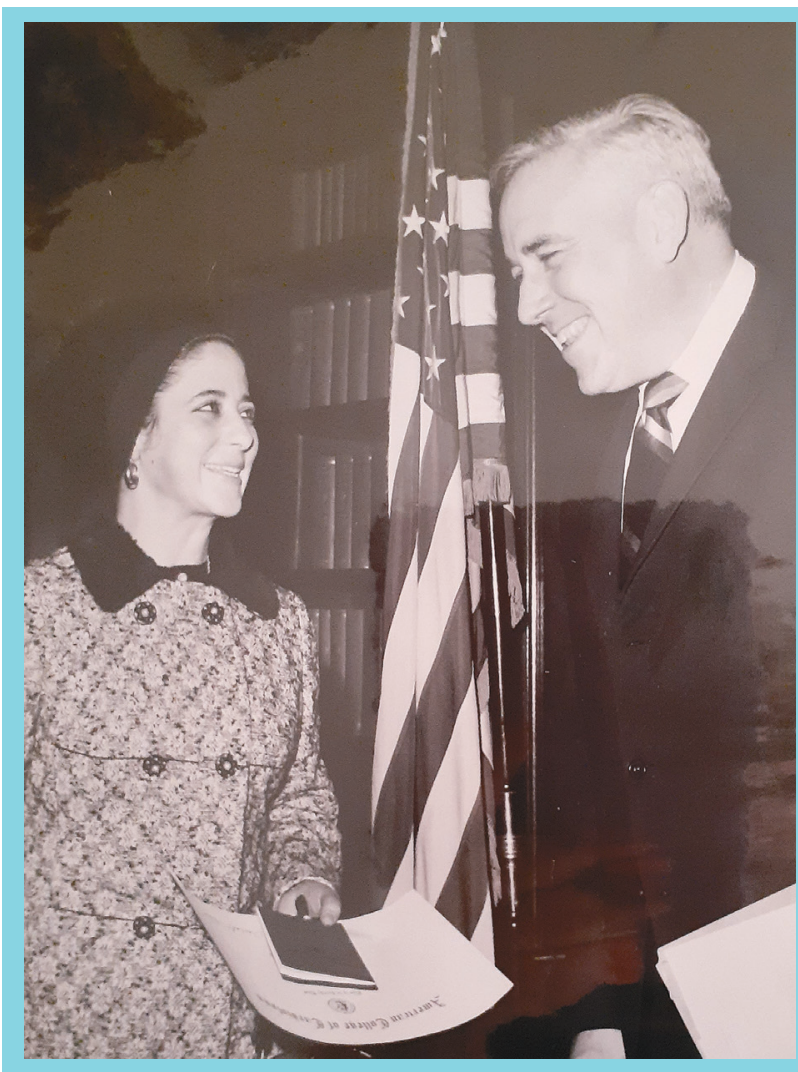

El embajador en Estados Unidos le entrega la distinción de Fellow del American College of Cardiology (ACC).

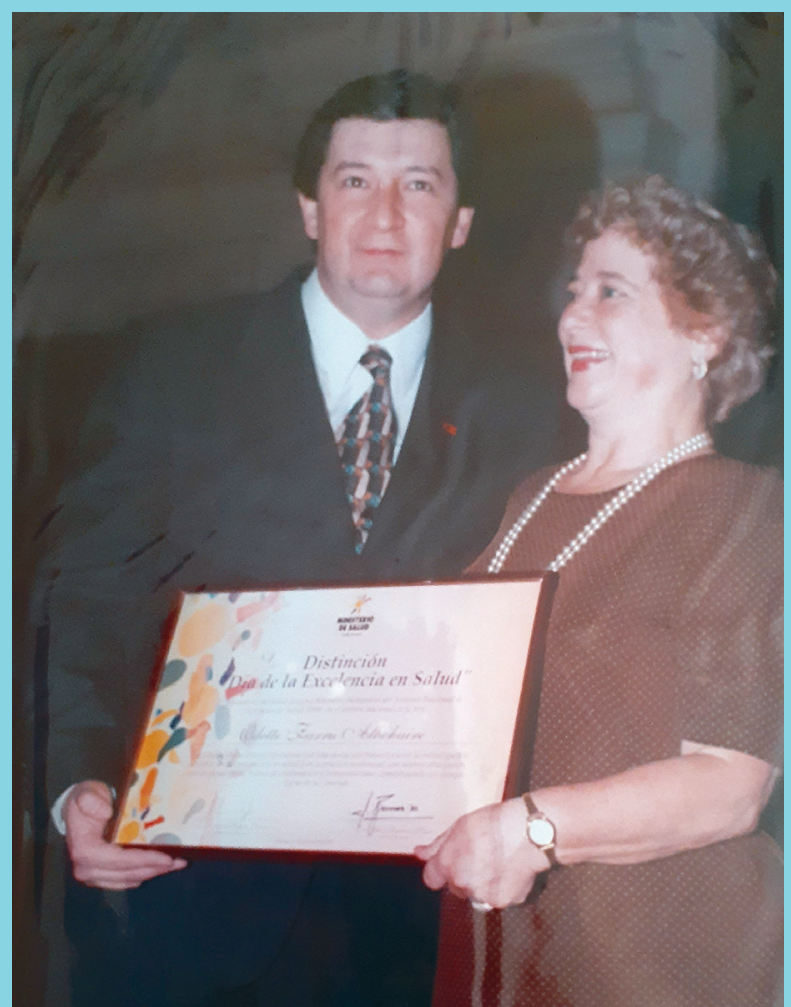

En la foto, el ex Ministro de Salud, Dr. Alex Figueroa, le confiere el título de "Miembro honorario del Sistema Nacional del Servicio de Salud", en 1998. de la Sochicar. En Francia hice clases en la Universidad de Lille. También en Alemania hice clases de posgrado. Fui nombrada Maestra de la Cardiología Chilena en el año 2013 por la Sociedad Chilena de Cardiología y Cirugía Cardiovascular. Recibí un reconocimiento muy especial de parte del Ministerio de Salud en 1998, donde se me nombró Miembro honorario del Sistema Nacional del Servicio de Salud en el ámbito nacional. Ese nombramiento fue muy importante y lo aprecio muchísimo, porque destaca la trayectoria en investigación científica, en capacitación de salud y práctica asistencial, premia el espíritu de sacrificio, ya que lo considera un ejemplo digno de ser imitado. Me llena de orgullo, porque es lo que yo hice, yo trabajé por los niños y para los niños. Otro hito que me enorgullece fue la creación (junto a una madre agradecida y por iniciativa de ella) de una Fundación llamada "Pro ayuda al niño cardiópata", con autorización del Ministerio de Salud. Con ella hacíamos una colecta anual, que nos permitió reunir dinero para complementar lo necesario para el Hospital. Con lo que juntamos, ayudamos a construir una sala de Hemodinamia, pabellones quirúrgicos, una UTI cardiológica pediátrica, hasta llegar hoy a ser un Servicio cardioquirúrgico con más de 60 personas trabajando en él, y a la vanguardia en la especialidad en este país.

Desde su experiencia, ¿qué consejo le daría a las nuevas generaciones?

Nuestro Centro cardiológico del Hospital Roberto del Río se convirtió en un centro de formación de cardiólogos pediatras en Chile. Presidí durante muchos años la comisión de postulantes a las becas de la Universidad de Chile. Una gran cantidad de brillantes becarios fueron formados por nosotros y hoy se encuentran en diferentes ciudades del país. También destaco la labor docente que hicimos en provincia y en el extranjero, donde se han formado muchos cardiólogos. En resumen, nuestro Centro ha sido una escuela formadora de especialistas con una mística docente muy particular. Bajo esa experiencia, el consejo que puedo darle a las nuevas generaciones es el siguiente: no hay solo que hacer lo que uno ama, si no que amar lo que uno hace, para ser productivo. Siempre van a faltar recursos materiales en nuestros hospitales, pero lo importante son los recursos humanos, las buenas ideas, la calidad de las personas. Si amamos con pasión lo que hacemos, tenemos casi solucionado el problema de la felicidad, por lo que pasión y esfuerzo es el consejo con lo que se logra todo. 